Laryngeal cancer occurs rarely in adolescents and young people. Castleman's disease is a rare lymphoproliferative disorder of uncertain etiopathogenesis and heterogeneous clinicopathological forms. Involved lymph nodes and extranodal lesions in the course of Castleman's disease may mimic malignant involvement. We report a case of an 18-year-old woman with T2NOMO laryngeal glottis cancer treated with definitive radiotherapy. During the irradiation, the patient underwent an excision of incidentally discovered left-sided enlarged cervical lymph nodes located outside the irradiated area. Coincidental hyaline vascular type of Castleman's disease was diagnosed. During six-year follow-up she has been free of cancer relapse and Castleman's disease symptoms.

Key words: laryngeal carcinoma, Castleman's disease, adolescent, radiotherapy, survival.

Contemp Oncol (Pozn) 2016; 20 (5): 421-424 DOI: $10.5114 /$ wo.2016.64608

\section{Castleman's disease mimicking lymph node metastases in a young woman with laryngeal cancer}

\author{
Krystyna Serkies, Małgorzata Łazar-Poniatowska, Joanna Seredyńska, \\ Wojciech Biernat, Jacek Jassem
}

Medical University of Gdansk, Poland

\section{Introduction}

Carcinoma of the larynx typically occurs in adult males. Primary risk factors for this tumour include active and passive smoking, alcohol abuse, and poor oral hygiene [1]. Human papilloma virus (HPV) and human immunodeficiency virus (HIV) infections, impaired immunity, gastro-oesophageal reflux disease, as well as several molecular abnormalities are additional risk factors for this malignancy [2]. The course of laryngeal cancer is strictly related to its location: cancers located in the glottis have relatively slow growth and low risk of nodal metastases. Among children and young adults, the disease, most frequently located in the glottis, is extremely rare. Laryngeal carcinoma in adolescents is believed to have particularly aggressive behaviour.

Castleman's disease (CD) is a noncancerous lymphoproliferative disorder of unclear aetiology [3-6]. This entity occurs in heterogeneous clinicopathological forms and comprises at least two distinct diseases: a unicentric CD (UCD; 90\%) subtype and a multicentric (MCD) subtype, which develops in both HIV-negative or HIV-positive patients. There are three classical histological subtypes of CD: a hyaline-vascular (HV, most common, 60\%), plasma cell (PC, 10\%), and mixed variants. The recently described plasmablastic subtype is associated with MCD and mostly with human herpes virus 8 (HHV-8) and HIV co-infection. Epstein-Barr virus infection may also result in nodal CD. Finally, immune disorders and autoimmunisation have been postulated as pathogenic factors of $C D$.

The unicentric HV variant of CD occurs mainly in adolescents as a slowly growing tumour located in the mediastinum or neck region [5, 6]. After surgical excision of the lesion recurrence is extremely rare. MCD, typically a PC subtype, occurs in adults and affects mainly peripheral lymph nodes. MCD represents a systemic disease with more aggressive behaviour and uncertain prognosis. MCD frequently manifests with systemic symptoms, such as fever, weight loss, weakness, and night sweats, considered to be a result of overproduction of interleukin-6 (IL-6) by lymph nodes (primary under influence of HHV-8) [5].

The coincidence of CD with solid tumours is extremely rare. We present a case of an 18-year-old woman who developed CD in cervical lymph nodes during radical irradiation for laryngeal cancer.

\section{Case report}

An 18-year-old woman with T2NOMO laryngeal cancer was admitted in October 2008 to receive radical radiotherapy. The patient reported an increasing hoarseness lasting for five months. She negated alcohol or tobacco use, laryngeal papillomatosis, and prior neck radiotherapy. Laryngoscopic examination revealed a lesion involving the left true vocal cord, left laryngeal pocket, and posterior part of the ventricle false cord. Biopsy of the lesion revealed moderately differentiated squamous cell carcinoma of the larynx 

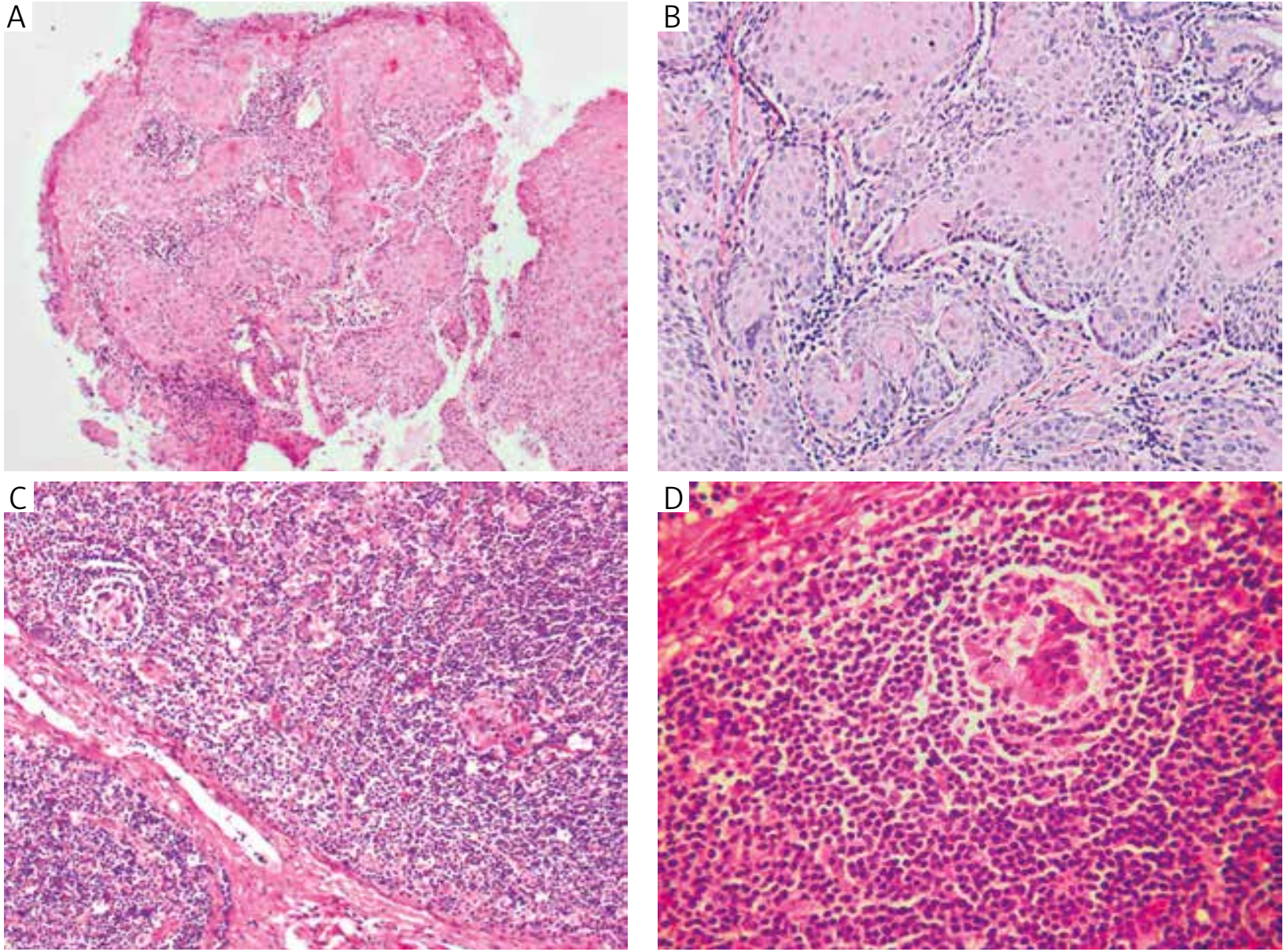

Fig. 1. Laryngeal squamous carcinoma was diagnosed from a small biopsy (A) that revealed well differentiated epithelial tumour with slight atypia and invasive growth into the fibrous stroma (B). Lymph node biopsy showed small, atrophic germinal centres surrounded by expansion of mantle zone and prominent interfollicular region (C). Typical "onionskin" pattern is visible at the germinal centre (D)

(Fig. 1A, B). CT demonstrated thickening of $8 \mathrm{~mm}$ of the left false vocal cord, shallowing the left laryngeal ventricle, and infiltration extending to the upper part of the vocal cord and small (up to $5 \mathrm{~mm}$ in the greatest diameter) unspecific lymph nodes of the neck. Staging work-up, including chest CT and ultrasound examination of the neck and abdomen, was negative for metastases. The patient was referred to radical radiotherapy with four lateral $6 \mathrm{MEV}$ photon beams $(5.5 \mathrm{~cm} \times 7.5 \mathrm{~cm})$ to the total dose of $66 \mathrm{~Gy}$ in 33 fractions. She started treatment two weeks after the diagnosis. Another laryngeal examination, performed on the first day of radiotherapy, showed previously absent infiltration of the anterior commissure and subglottis. Owing to these findings, after delivering $6 \mathrm{~Gy}$, the lower radiation fields were extended by $0.5 \mathrm{~cm}$. Additional $\mathrm{CT}$, performed for radiotherapy modification revealed previously absent, enlarged, left-sided cervical lymph nodes of the second group, outside the irradiated region. An ultrasound of this region showed enlarged lymph nodes with a central hyperechoic area. The biggest lymph node was $2.5 \mathrm{~cm}$ in diameter and was localised at the left mandibular angle. Radiotherapy was resumed after a three-day pause. The patient refused fine-needle aspiration biopsy of the neck lymph node. PET-CT performed without inter- rupting radiotherapy revealed metabolically active lesions in the larynx and in the left cervical lymph nodes at the level of the third cervical vertebra (SUV of 3.8 and 2.4, respectively). After 19 fractions the enlarged cervical lymph nodes were removed. The surgery caused an additional four-day pause in radiotherapy. The tissue material contained two lymph nodes (17 and $12 \mathrm{~mm}$ in diameter), with macroscopic features of typical reactive inflammatory response. Histopathology examination showed HV type of CD (Fig. 1C, D). During six-year follow-up, she has been free of cancer recurrence and $C D$ disease symptoms.

\section{Discussion}

Laryngeal carcinoma in patients aged below 40 years accounts for less than 3\% of all laryngeal cancer cases [7-9]. The rarity of the disease among adolescents hampers the diagnosis and may lead to delay in treatment, as was the case in our patient. It has been estimated that in glottis cancer patients a one-month delay from the onset of symptoms to start of radiotherapy was equivalent to a $4.5 \%$ decrease in recurrence-free survival [10].

The management of laryngeal cancer in young people is similar to that in adults. Radiotherapy continues to be the 
preferred method, allowing in most cases preservation of laryngeal function and voice. On the other hand, this modality is associated with the risk of post-irradiation effects including second malignancies. The patient presented in this report received conventional radiotherapy at a dose of $66 \mathrm{~Gy}$ to a region confined to the larynx. As recently reported, a 13-year-old boy with T2NOMX moderately differentiated HPV-positive squamous cell carcinoma of the glottis was administered a hyperfractionated dose of 81.6 Gy [11].

Diagnosis of CD is based on histological evaluation of lymph nodes, but fine-needle biopsy may be sufficient to confirm CD in the extranodal sites, although it is challenging for the pathologist. On clinical examination and radiological images, CD can mimic various lesions, including malignant disorders [12-14]. If accompanied by cancer, it may be misdiagnosed as progression or recurrence. Specific calcifications may occur in the HV type; however, as in our case, they are usually absent from the involved lymph nodes. Intensively enhancing CD-involved nodal masses present in CT scans can be difficult to distinguish from lymphomas or cancer metastases. PET is helpful in resolving ambiguous CT findings [6]. As in our patient, SUV values of CD-involved lymph nodes are lower than those typical for lymphoma or cancer metastases.

The association between CD and cancer remains unclear. Several authors suggested that CD is associated with an increased risk of lymphomas and lymphoma-associated diseases $[15,16]$. HHV-8 infection, typical for MCD, is often present in AIDS patients with or without Kaposi sarcoma, and those with other lymphomas. It was suggested that IL- 6 and VEGF are the paracrine factors related to CD involved in carcinogenesis of malignant tumours that coexisted with $C D[5,17]$. Anecdotal coincidences of $C D$ with lymphomas, B-cell non-Hodgkin, and Hodgkin lymphomas and with multiple myeloma were reported $[18,19]$. A few reports described co-existence of CD (frequently unicentric and HV type) and solid neoplasms including ovarian, colorectal, bladder, renal, lung and tongue cancer, hepatocellular carcinoma, and retroperitoneal leiomyosarcoma, diagnosed in both early or advanced stages of disease [17, 20-25].

To our knowledge this is the first published report of the co-existence of CD and laryngeal carcinoma. The possible relationship between $C D$ and this rare case of laryngeal cancer in an adolescent remains unclear. Castleman's disease should be kept in mind as a differential diagnosis for nodal enlargement.

The authors declare no conflict of interest.

\section{References}

1. Maasland DH, van den Brandt PA, Kremer B, Goldbohm RA, Schouten LJ. Alcohol consumption, cigarette smoking and the risk of subtypes of head-neck cancer: results from the Netherlands Cohort Study. BMC Cancer 2014; 14: 187. doi: 10.1186/1471-240714-187.
2. Niu J, Huang YJ, Wang LE, Sturgis EM, Wei Q. Genetic polymorphisms in the PTPN13 gene and risk of squamous cell carcinoma of head and neck. Carcinogenesis 2009; 30: 2053-8.

3. Bowne WB, Lewis JJ, Filippa DA, Niesvizky R, Brooks AD, Burt ME, Brennan MF. The management of unicentric and multicentric Castleman's disease. Cancer 1999; 85: 706-17.

4. Casper C. The aetiology and management of Castleman disease at 50 years; translating pathophysiology to patient care. $\mathrm{Br} J$ Haematol 2005; 129: 3-17.

5. Cronin DM, Warnke RA. Castleman disease: an update on classification and the spectrum of associated lesions. Adv Anat Pathol 2009; 16: 236-46.

6. Madan R, Chen J-H, Trotman-Dickenson B, Jacobson F, Hunsaker A. The spectrum of Castleman's disease: Mimics, radiologic pathologic correlation and role of imaging in patient management. Eur J Radiol 2012; 81: 123-31.

7. Prasad KC, Abraham P, Peter R. Malignancy of the larynx in a child. Ear Nose Throat J 2001; 8: 508-11.

8. Rutt AL, Hawkshaw MJ, Sataloff RT. Laryngeal cancer in patients younger than 30 years: a review of 99 cases. Ear Nose Throat J 2010; 89: 189-92.

9. Shvero J, Hadar T, Segal K, Abraham A, Sidi J. Laryngeal carcinoma in patients 40 years of age and younger. Cancer 1987; 60: 3092-5.

10. Hansen O, Larsen S, Bastholt L, Godballe CH, Jorgensen KE. Duration of symptoms: impact on outcome of radiotherapy in glottis cancer patients. Int J Radiat Biol Phys 2005; 61: 789-94.

11. Joos B, Joos N, Bumpous J, Burns C, French ChA, Farghaly H. Laryngeal squamous cell carcinoma in a 13 year-old child associated with human papillomaviruses 16 and 18: a case report and review of the literature. Head and Neck Pathol 2009; 3: 37-41.

12. Hakimi AA, Faiena I, Kaleya RN, Ghavamian R. Retroperitoneal Castleman's disease. Urology 2010; 76: 1379.

13. MacDonald SR, Lurain JR, Hoff F, Variakojis D, Fishman DA. Castleman disease presenting as a pelvic mass. Obstet Gynecol 1996; 87: 875-7.

14. Petrina A, Eugeni E, Badolato M, Boselli C, Covarelli P, Rondelli F, Noya G. Unicentric Castleman's disease approached as a pancreatic neoplasm: case report and review of literature. Cases J 2009; 2: 9090.

15. Abdel-Reheim FA, Koss W, Rappaport ES, Arber DA. Coexistence of Hodgkin's disease and giant lymph node hyperplasia of the plasma-cell type (Castleman's disease). Arch Pathol Lab Med 1996; 120: $91-6$.

16. Nicoli P, Familiari U, Bosa M, et al. HHV8-positive, HIV-negative multicentric Castleman's disease: early and sustained complete remission with rituximab therapy without reactivation of Kaposi sarcoma. Int J Hematol 2009; 90: 392-6.

17. Chun YS, Calderaro J, Zucman-Rossi J. Synchronous hepatocellular carcinoma and Castleman's disease: the role of the interleukin-6-signaling pathway. Hepatology 2012; 56: 392-3.

18. Unsal Tuna EE, Ozbek C, Arda N, Ildogan E, Dere H, Ozdem C. Development of a Hodgkin disease tumor in the neck of a patient who previously had undergone complete excision of a hyaline-vascular Castleman disease neck mass. Ear Nose Throat J 2010; 89: 20-3.

19. Yuan Z, Dun X, Li Y, Hou J. Treatment of multicentric Castleman's disease accompanying multiple myeloma with bortezomid: a case report. J Hematol Oncol 2009; 2: 19-22.

20. Bertero D, Buzio M, Albertino B, Giaccone M, Ricci E. A case report of Castleman's disease in a patient with endometrioid adenocarcinoma of the ovary. Minerva Chir 1991; 46: 989-93.

21. Chan J, Loh A, Sim H, Tan MH, Toh ChK. Coexistence of unicentric Castleman's disease and locally advanced papillary renal cell carcinoma: more than a coincidental association? Ann Acad Med 2010; 39: 584-5.

22. Deshmukh M, Ball M, Deshpande P, Jambhekar NA. Synchronous squamous cell carcinoma of tongue and unicentric cervical Castleman's disease clinically mimicking a stage IV disease: a rare association or coincidence? Head Neck Pathol 2011; 5: 180-3.

23. Gomez-Raposo C, Nistal M, De Castro Carpieno J, Rotunda GS, Belda-Iniesta C, Casado E, Baron MG. Retroperitoneal Castleman's 
disease with colon cancer. A rare association. Clin Transl Oncol 2008; 10: 238-40.

24. Horio H, Hjima T, Sakaguchi K, Kuwabara K. Mediastinal Castleman disease associated with pulmonary carcinoma, mimicking N2 stage lung cancer. Jpn J Thorac Cardiovasc Surg 2005; 53: 286-9.

25. Ikari J, Kojima M, Tomita K, et al. A case of IgG4-related lung disease associated with multicentric Castleman's disease and lung cancer. Inter Med 2010; 49: 1287-91.

\section{Address for correspondence}

\section{Krystyna Serkies}

Medical University of Gdansk

Dębinki 7

80-211 Gdańsk, Poland

e-mail: kserkies@gumed.edu.pl

Submitted: 27.10 .2014

Accepted: 14.04 .2015 